\title{
Social Pharmacology: A Further Step in Public Health
}

\author{
José-Luis Alloza*
}

Department of Biomedical Sciences, School of Medicine and Health Sciences, The University of Alcala de Henares, E-28871 Alcala de Henares, Madrid, Spain

\begin{abstract}
Social Pharmacology is a field of health science which generates knowledge about marketed drugs in actual use; it focuses on evaluation of the social consequences of an individual's exposure to any marketed drug and factors related to its utilization.. The goal of this discipline is to gain knowledge still needed after a drug is marketed. The dossier of a new medicine following regulatory approval contains only the beginning of information needed to be gathered. The postmarketing period represents the most extensive opportunity to study medications in their "social life cycle" The postapproval environment is complex: strict drug development process controls are no longer in place and operational and management actions by industrial sponsors, health delivery agencies and regulators are unpredictable. We review the impact of social pharmacology on public health in its broadest scope. Social pharmacology is proposed as a strategic means to obtain essential data about marketed drugs by engaging the expertise of heterogeneous groups of health-related disciplines., By assessing the wide scope of potential interactions between vectors linked to the actual use of marketed drugs, population-based conclusions may be reached about risk-benefit factors, need for alert responses, proposed actions for decision-making, importance of negative drug effects, and promotion of proper and efficient use of drugs .
\end{abstract}

Keywords: Clinical pharmacology, clinical research, observational studies, outcome research, Phase IV, public health, social pharmacology, social research.

\section{DEVELOPMENT, GROWTH AND STRUCTURE OF SOCIAL PHARMACOLOGY}

Issues concerning drugs go beyond pure science. Today, most of the population is better educated in health matters, as well as about the quality of care they need or deserve. Users of drugs and/or other pharmaceutical products are deeply involved in therapeutic decisions and participate in them by offering their opinions. When patients need it, they request information from experts either personally or using the internet.

Today, drugs are a desired commodity by the public, calling for a better quality of life and well-being. In developed countries, drugs are not only designed to prevent and cure major diseases, but also to meet needs related to hygiene, personal or aesthetic appearance, or reducing any mild suffering, to allow citizens to enjoy the fullness of life. Laying out the coordinates that allow us to establish stable relationships between the medication prescribed by the physician, self-medication and the health demands exerted by the society is becoming progressively more difficult.

The social sciences have a wide scope of objectives but probably the major one is to study relationships between individuals in order to achieve a better understanding of society. Moreover, many social sciences, such as sociology,

*Address correspondence to this author at the Department of Biomedical Sciences, School of Medicine and Health Sciences, The University of Alcala de Henares, E-28871 Alcala de Henares, Madrid, Spain;

Tel: + 3491741 5165; E-mail: josel.alloza@uah.es anthropology, community psychology and behavioral science must be taken into account in a cross-cultural context. In this review, our aim is to establish a new link between social sciences and health sciences, using the discipline of Social Pharmacology to open the horizons of the social science fields and foundations to a public health approach. Table 1 shows the many social science disciplines which are health related.

Social Pharmacology or Sociopharmacology, a new field within Clinical Pharmacology, describes the relationships between the individual, society and medicinal products. It was probably Dr. C.W.M. Wilson of the Department of Pharmacology at Trinity College (University of Dublin) the first who coined the term "Social Pharmacology". [1]. The term "Sociopharmacology" began to be used in the 60's when researchers realized it was necessary to assess the effects of drug addiction on the mood and behavior of individuals in social settings (primarily psychotropic and drug abuse agents) [2]. This name is still used by several researchers restricted to drug abuse circumstances and social behavior impact [3].

However, the newer direction and development of Social Pharmacology started in the 80's and largely matches Dr. Wilson's usage [4-10]. Since then, the concept of Social Pharmacology has evolved and this new discipline explores the multiple dimensions of medical drug use during the postmarketing period. Thus, this discipline has expanded its horizons and enriched the specialty by incorporating contributions from physicians, pharmacists, nurses, biologists, drug epidemiologists, health economists, lawyers, 
Table 1. Social sciences identified with health-related subjects.

\begin{tabular}{|c|c|c|}
\hline Social Medicine & Social Security & Social Behavior \\
\hline Social Pharmacy & Social Psychology & Social Gerontology \\
\hline Social Epidemiology & Social Science & Social Statistics \\
\hline Sociochemistry & Social Anthropology & Social Informatics \\
\hline $\begin{array}{c}\text { Social Pharmacology } \\
\text { (or Sociopharmacology) }\end{array}$ & Social Ecology & Social Research \\
\cline { 2 - 3 }
\end{tabular}

Table 2. Health care disciplines associated with social pharmacology.

\begin{tabular}{|c|c|c|c|}
\hline Academician & Environmental health & Nurse & \\
\hline Ambulatory care pharmacist & Epidemiologist & $\begin{array}{l}\text { Marketing health-related } \\
\text { products/services }\end{array}$ & Pharmacoeconomics \\
\hline Anthropologist & Ethnopharmacologist & \multirow{2}{*}{ Medical doctor, specialist } & Pharmacologist \\
\hline Biologist & Gerontologist & & Physician's assistant \\
\hline Behavioural analyst & Health insurance & Medical computing specialist & Psychologist \\
\hline Biometrician & Health policy & Medical computing \& coding & Preventive medicine \\
\hline Clinical pharmacologist & $\begin{array}{c}\text { Health professional education \& } \\
\text { certification }\end{array}$ & Medical informatics specialist & Primary care physician \\
\hline Computer-based patient records expert & Health promotion & $\begin{array}{l}\text { Medical community services } \\
\text { program coordinator }\end{array}$ & Public health officials \\
\hline Community psychologist & Health services research & Medical sociologist & Social medicine \\
\hline Consumer organizations & Health statistics & $\begin{array}{c}\text { Newspaper, radio and television } \\
\text { journalist }\end{array}$ & Social workers \\
\hline Drug use process & Hospital pharmacist & Patient educator & Social psychologist \\
\hline Ecologist & Internet expert & Pharmaceutical industry experts & Sociologist \\
\hline Economist & Legislator & Pharmacoecologist & Statistician \\
\hline Educator & Lawyer & & Political scientist \\
\hline \multirow[t]{3}{*}{ Environmental chemist } & Mass media & & Quality assurance techniques \\
\hline & & & Teacher \\
\hline & & & Veterinary medicine \\
\hline
\end{tabular}

regulators, insurance specialists, and communication specialists (Table 2).

Social Pharmacology had its formal introduction in an international reference book with multiple authors, a source document for those seeking to conduct research on this subject [11] (Fig. 1).

\section{DRUG PRODUCTS AND PUBLIC HEALTH}

When focusing on development of a drug product, two stages reveal significant contrasts: the postmarketing setting of a new drug is completely different from the development stage in which rigorous scientific methods are employed.
There is a great contrast between ideal clinical research conditions during the drug's clinical development and those of its new "habitat" -the real world "jungle" in which it will be put to use. From the point of view of the consumer and society, external circumstances such as differences in cultural background, hygiene, education, ability to understand, and inter-individual response need to be considered. These create a wide and deep pool of inputs about drug use, which include those social factors which could explain how and why drugs are used outside clinical and rational healthcare frameworks.

Social Pharmacology studies marketed drugs in a pluralistic society within a multidisciplinary structure. All 


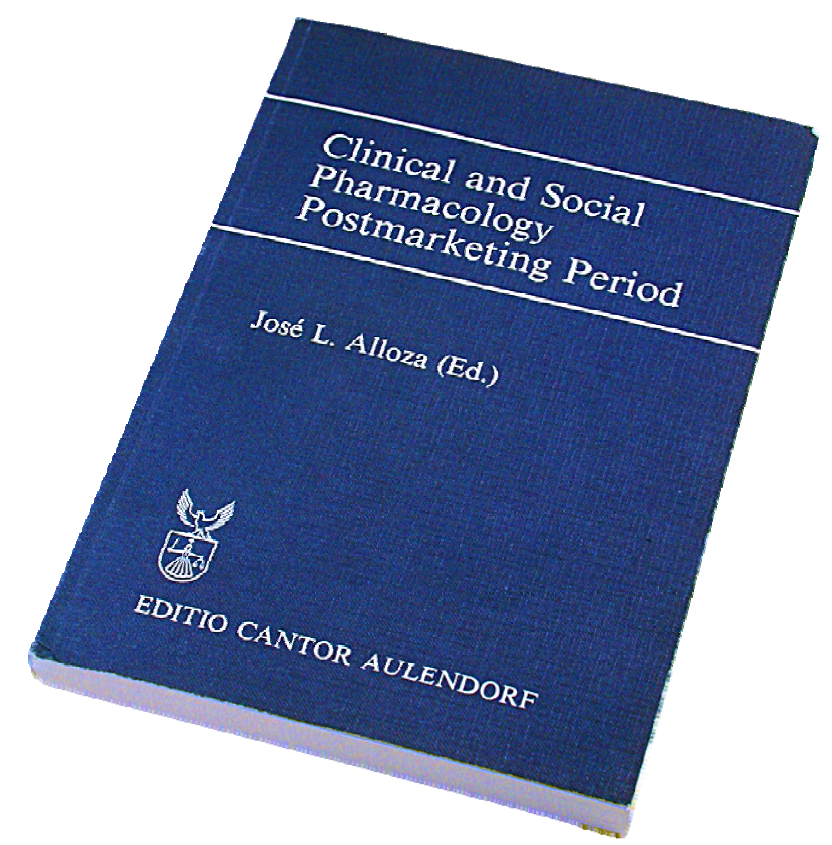

Fig. (1). Reference book of "Social Pharmacology" (1985).

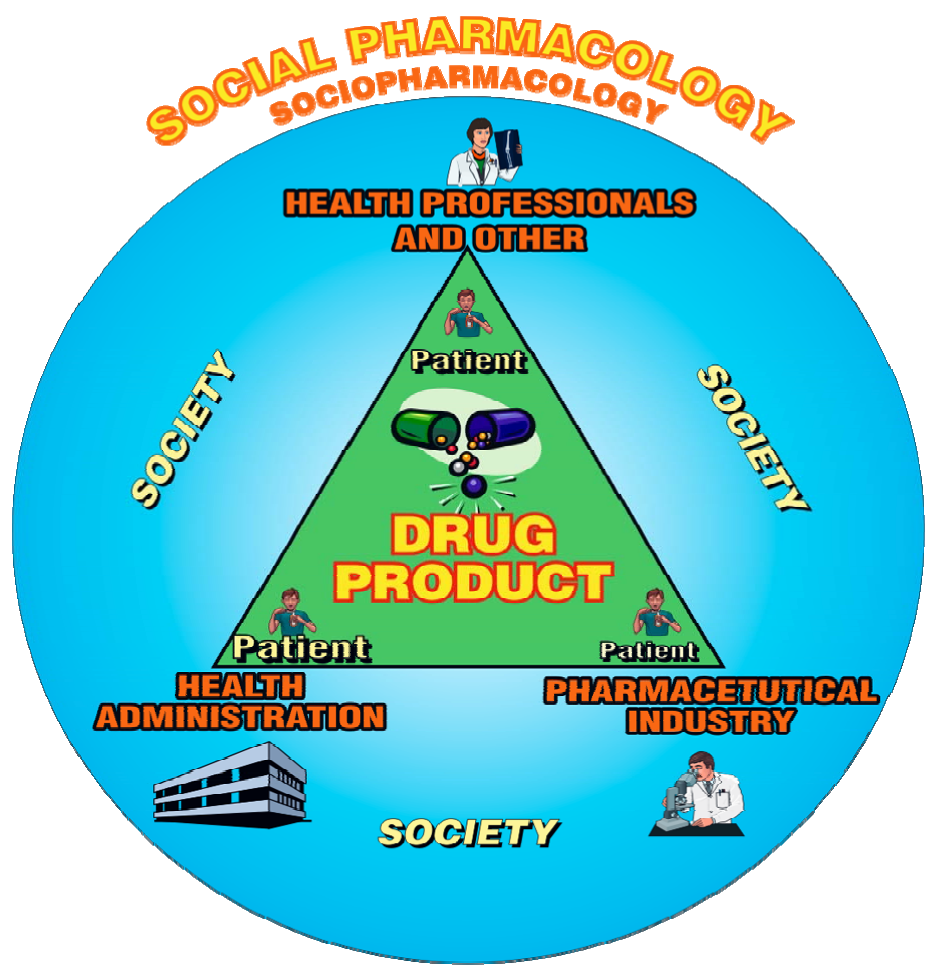

Fig. (2). Social Pharmacology and its components (Source: Alloza JL. Social Pharmacology: Conceptual remarks. Drug Information Journal 2004; 38: 321-329).

types of professionals who directly or indirectly participate in health care and public health, either by providing a service or improving drug therapy (information, communication, education, problem solving) are included. Therefore, the list of methodological approaches is very extensive: pharmacoepidemiological studies in drug surveillance, experimental and observational studies ("naturalistic"), studies of drug response variation, outcomes research, pharmacoeconomic studies, drug-toxicity evaluation, drug regulation evaluation, drug information evaluation, etc. In (Fig. 2), Social
Pharmacology and its components are represented by the triangle. The drug product is represented as the center of interest and the three stakeholder groups, health professionals, health authorities and the pharmaceutical industry, are represented at the vertices.

Social Pharmacology represents a broad knowledge base related to the core of Public Health, including: efficacy, safety, effectiveness, and efficiency of pharmaceutical products; related information on drug details, patient 


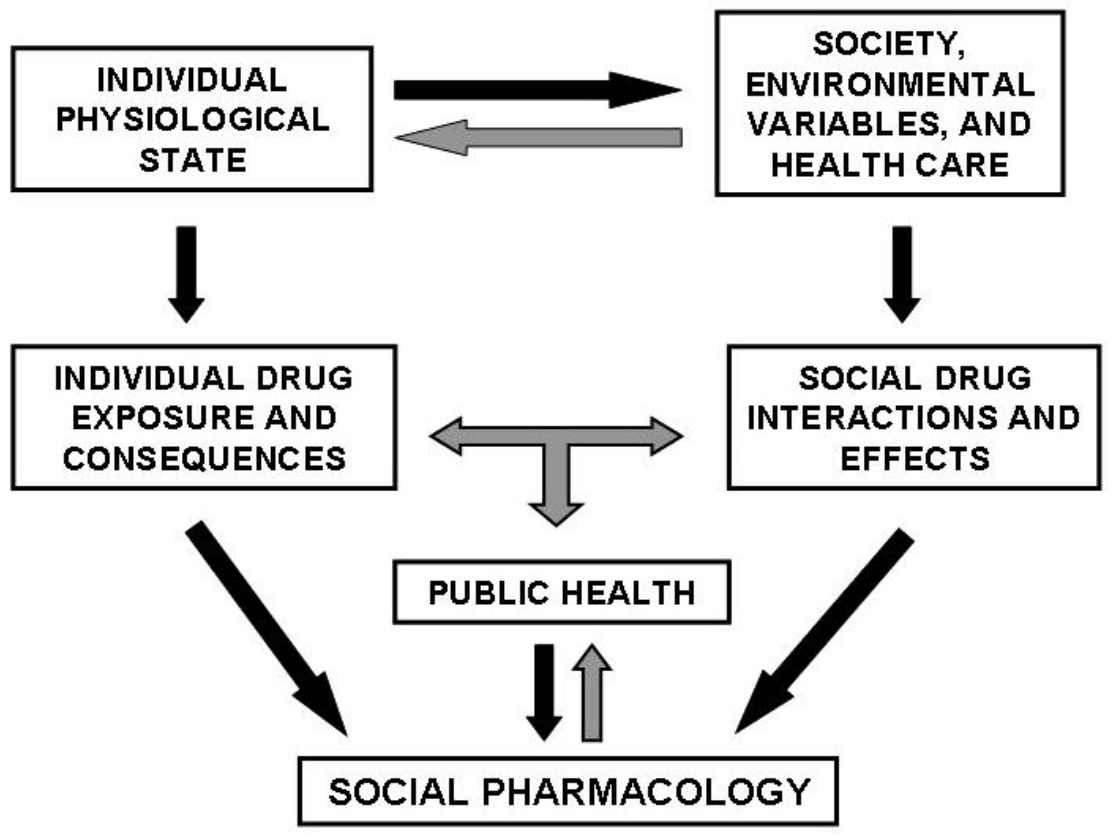

Fig. (3). Interrelationships among society, public health and social pharmacology.

compliance, self-medication and user habits; attitudes towards drug products; utilization of economic resources; issues related to rational drug therapy such as the application of evidence-based treatment guidelines; issues related to drug response variation (polymorphisms, pharmacogenetics) measures to determine drug over- and under-utilization; drug use profiles involving both patients and populations; medication safety as both a clinical function and infrastructure requirement; the role of quality assurance tools (drug formularies and drug utilization review); methods for supplying accurate information pertaining to public health through private sector; compilation and dissemination of guidelines based on evidence-based medicine.

Many epidemiological studies on drugs and populations are conducted by public health or preventive medicine departments, which provide information on the value of a medicine in the assessment of risk-effectiveness balance. Inadequate drug consumption and poor compliance to the defined therapeutic regimen are examples of low health-care seeking behavior present in a "medicalized" society even in countries with well-established healthcare systems [12]. In (Fig. 3), the place of public health when the individual and the corresponding society are exposed to drug products is depicted.

\section{SOCIAL PHARMACOLOGY AS A RESEARCH DISCIPLINE}

Social Pharmacology is not an "exclusive" body of knowledge on drug products restricted to specific professional goals. Neither is it restricted to the "social pharmacologist". Nor is it connected with "social exclusion" in reference to the concept of poverty, Managed Care (HMO, Medicare, Health budgets...) nor mental health / behavioral health. In addition, Social pharmacology is not only the study of substance abuse, drug dependence, chemical dependence and their social consequences. It includes disease management, that is, a coordinated health care process that seeks to manage and improve the health status of a carefully defined patient population over the entire course of a disease. Further, it includes postmarketing surveillance, the systematic screening for adverse drug effects or clinical effectiveness studies,

Consequently, Social Pharmacology includes a) evaluation of the social consequence of an individual's exposure to any marketed drug b) on-going research into marketed drugs now being undertaken in consumer society in order to gain value-added knowledge on these drugs and their actual use, issues which could not be addressed during the clinical and drug development phases, c) studies of those social factors which could explain how and why drugs are used outside clinical and rational healthcare frameworks and d) includes an analysis of the relationships between the pharmaceutical industry, health administration, health professionals and society.

\section{SOCIAL PHARMACOLOGY, METHODS AND EXAMPLES}

Patients take drugs for medical reasons, as a part of their own self-care, and possibly without common sense, as a fashion, or based on beliefs. The results of drug research lead to the study of other new chemical entities, create knowledge, and, of course, generate profits for the industry and become the object of scientific maneuvering and crosscultural interventions.

The purpose of Social Pharmacology is (a) identify disciplines and issues that influence drug outcomes in patients and society that lie beyond fundamental findings generated by clinical trials, and (b), suggest the need for 
integrating methods and policies that might be cost-effective in improving the social value of the whole process. When discussing the performance of research in the broad context of a marketed drug, Social Pharmacology means the study of any drug product used in a modern society and of understanding how society actually uses medicines. Moreover, it represents a new approach to drugs in the postmarketing period, involving research (on the individual and social level) into the "real life" of drugs in the community and evaluates the consequences for society, health administrations, health-care services and drug manufacturers.

To carry out research within these complex circumstances, the methodology of Social Pharmacology may be conceived of as an integrative system that summarizes major determinants of drug use in a particular environment, and their interrelationships. The appraisal and management of marketed drugs by the health professions and society is directed at maximizing the benefits of therapy while minimizing negative personal and economic consequences. Thus, benefits of drug therapy are to be optimized and negative aspects (toxicity, adverse effects, interactions, etc.) are to be minimized for the individual patient at an economic and social level.

Hence, Social Pharmacology is also an operative system that integrates the interrelationships among health professionals (physicians, pharmacists, nurses, veterinary surgeons, epidemiologists, anthropologists, etc.) and other professionals (lawyers, economists, educators, journalists, statisticians, computer engineers, legislators, etc.) with individual patients and society as a whole. Social Pharmacology also includes the economic assessment of drug utilization for clinicians, patients, and the third parties involved in paying for prescription drugs.

Social Pharmacology utilizes established methods for evaluating the use of medicinal products and their consequences. The scope of research is very large. The following, therefore are the major methods applicable:

\section{1) EXPERIMENTAL AND OBSERVATIONAL STUD- IES}

a. Pharmacoepidemiologic studies: Studies of the safety of drugs (postmarketing drug surveillance) or those related to their consumption, prescription and use [13, 14].

b. Experimental studies (pragmatic, controlled clinical trials) and observational studies (such as cohort studies or case-control studies).

c. "Naturalistic" studies in typical healthcare practice settings and the clinical evaluation of non-approved indications of the drug $[15,16]$.

d. Longitudinal studies on the development of the disease (whether or not they are concomitant with the administration of a certain drug), as well as long-term efficacy studies.

e. Post-marketing studies on safety and efficacy to establish the incidence of known adverse reactions in the population, or those which rarely occur. Also studies related to over-dosage and under-dosage as well as overuse of drugs and drug misuse [17- 20].

f. Drug utilization review $[21,22]$.

\section{2) DRUG THERAPY AND HEALTH OUTCOMES}

a. Treatment audits and other overall evaluations of healthcare [23].

b. Treatment compliance analysis and evaluation [24, 25].

c. Quality improvement evaluations on prescription, dispensing, and follow-up.

d. Development of treatment formularies and drug formulary construction $[26,27]$.

e. Therapeutic guidelines and clinical practice parameters, as well as patient guidelines [28, 29].

f. Assessment of product package inserts (PPI).

g. Pharmacoeconomic studies, as well as studies of the social cost of drugs [30, 31].

h. Outcomes, quality of life, and patient satisfaction research [32, 33].

\section{3) UNDESIRABLE EFFECTS AND RESPONSE VARI- ATION}

a. Evaluation of cases of acute drug toxicity and toxicity in special populations. Evaluation of risk interventions. Evaluation of the practical information on toxicity, generating clinical decisions concerning risk/benefit.

b. Analysis of drug interactions with food, nutriceuticals, functional foods, probiotics, and other drug products, and with recreational drugs [34].

c. Studies on the prevention of iatrogeny [35].

d. Studies on the variability in response due to pharmacogenetic reasons and of patient morbidity $[36,37]$.

e. Evaluation of the customized prescription (personalized treatment) in a pharmacogenetic setting.

f. Studies on the role of appropriate titration (up/down) with regard to the patient's medical condition.

g. Quantitative analysis of medicinal product habituation and dependence.

h. Studies on adjusting dosage to human biological rhythms / chronotherapeutic approach [38].

\section{4) RISK OF DRUG TREATMENT AND PATIENT ASSESSMENT}

a. Studies on drugs taken by at-risk populations, especially pregnant women, nursing mothers, infants 
and children, the elderly, patients with chronic diseases (e.g., diabetes and renal, hepatic, cardiovascular and psychiatric diseases) $[39,40]$.

b. Studies of the compassionate use of drugs that are under development and for nonregistered drug uses.

c. Analysis of errors in the use, prescription, dispensing, and formulation of drugs [41, 42].

d. Studies of drug compounding as the subject of permanent evaluation [43].

e. Pharmacological evaluation of self-medication with over-the-counter drugs (OTC) and phytotherapy (herbal medicines) [44-46].

f. Evaluation of social health issues of dietetic and cosmetic products, as well as medicines, medical devices and prosthetic devices [47].

g. Evaluation of the impact of "orphan drugs" designed to deal with "orphan diseases" in society.

h. Evaluation of the use of medicinal products for veterinary use, as well as herbicides, pesticides, residential cleaning products and their toxicological consequences.

i. Studies of the interactions between scientific medicine, false claims, quack-remedies, alternative medicine, and placebo effects [48-50].

\section{5) SOCIAL BEHAVIOR AND INDIVIDUAL IMPACT OF DRUG PRODUCTS}

a. Analysis of consumer association requests, demands and suggestions related to drugs.

b. Quality assessment of contributions of patient associations for drug information and treatment with medications.

c. Evaluation of patient interactions and relationships with health professionals and the pharmaceutical industry [51-53].

d. Evaluation of the quality of therapeutic and health information and ways to provide information on the appropriate use of medicinal products [54-56].

e. Evaluation of ways to develop and promote patient health education for the appropriate use of drugs.

f. Establishment of quality criteria and objectives for the management of medicines and continuing education for health professionals.

g. Evaluation of health coverage and management of medicines by the media (television, radio, newspapers) [57, 58].

h. Systematic evaluation of the accuracy of the internet information concerning prescription drug products, including false and misleading information [59-61].

i. Measurement of the social impact of new drugs.
6) MISLEADING INFORMATION AND MISUNDERSTANDINGS

a. The study of prescribing "off-label" and unregistered indications.

b. Studies on prevention and isolation of fraudulent drug products intended to deceive: Strategies to deal with and fight counterfeit drugs.

c. Analysis of inter-professional communication and of the similarity of terms in public health materials used by doctors, clinical pharmacologists, pharmacists and patients.

d. Analysis of pharmaceutical drug promotion $[62,63]$.

e. Evaluation of the clinical and social implications of drug use for non-medical purposes.

f. Studies preventing doping using natural products, banned substances or medicinal ingredients.

g. Quantification and impact of regulation by health authorities (regional, national, European Union, National Institutes of Health, Food and Drug Administration) on society [64].

h. Evaluation and analysis of health interventions incorporated into national health systems as a result of government policies and the impact of insurers' administrative regulations on clinicians' efforts to achieve appropriate drug therapy.

i. Analysis of the pros and cons of electronic medical data (prescription, medical records, protocols, information)[65].

j. Studies of ethical issues, the protection of end users and written informed consent.

\section{DISCUSSION AND CONCLUSION}

This review has emphasized those aspects of Social Pharmacology which have particular relevance to public health issues as they relate to the "life cycle" of a product. This is the period when there is the opportunity to obtain new knowledge derived from the results of various health evaluation studies in progress. Such results provide added value to the product in terms of public health benefit as, for example, information for decision makers in a national health system.

Phase III of the drug development cycle, the period when the final dossier for a new drug product is completed and approved by the Regulatory Agency, is followed by Phase IV or the postmarketing period when Social Pharmacology research is implemented. The meaning of Phase IV for regulators or the pharmaceutical industry is limited because their goal during this period is oriented toward regulatory and strategic concerns about marketing the new product. This goal is very different from the needs of public health and society as presented above. Unless there is an opportunity to evaluate new indications, which could lead to expanded markets, the industry is usually no longer interested in the many questions which fall under the 
umbrella of Social Pharmacology. As indicated by Louis Lasagna M.D., Sc.D., often called the "father of clinical pharmacology": "Drug development is an ongoing process; it does not stop because a drug is registered. Information about a drug is never complete." [66]. By pursuing studies to evaluate the benefits or risks of a marketed drug for the patient, the society, administrative bodies and decision makers, as well as providing a basis for taking action in the global scenario of the pharmaceutical industry and public health, Social Pharmacology fulfills this need for information.

The objectives of Social Pharmacology include studies reflecting the "real life" of a marketed drug, as well as the constantly evolving "life cycle of the drug in its habitat". Neither of these subjects is typically considered by Regulatory Agencies such as the FDA or EMA. However, conclusions based on these factors are important in setting the value of a medication in the social environment and can illustrate the aims of Social Pharmacology from the regulator's point of view. An apparently minor example but one that can be important to the patient, is the so-called "nonpharmacological basis" of a treatment. In the doctor's office, patients frequently focus on the color, shape, taste, label and other details of a medicine. Pharmaceutical companies go to great lengths to ensure that doctors think of brand-name products when they write prescriptions. Ambiguous promotion of many types of medical products (OTC, prescription products, nutraceuticals, hygiene products) may make the individual and society prone to "medicalization" - trying to solve non- medical problems with medicines, believing that there is a "pill for everything".

Social Pharmacology may be compared to a puzzle in which all of the pieces are important to build the complete picture of the individual exposure / response to marketed drugs and public health as the outcome. In our modern world, Social Pharmacology as a health science is interdisciplinary, with wide horizons capable of integrating the findings of different professionals in order to maximize achievement of Public Health goals.

The number and scope of studies that remain to be done under the paradigm of Social Pharmacology is impressive, and specialization is common. Listing the many examples in this presentation should contribute to expanding the seeding objective for such studies. Basically, output from research in Social Pharmacology has social consequences, such as: gathering public health indicators, results in effectiveness and safety, therapeutic results for the patient when exploring possible new indications for added value to some drug products, results in drug efficiency, as well as implementation of drug information. Moreover, it also fosters communication between researchers working in different settings, within and outside academic institutions, in the private sector, applied fields, etc. For instance, subjects for discussion might range from choosing the correct dose for a given patient, the impact of the internet on drug use, to how to build a drug formulary. Today, Social Pharmacology is a well-established discipline, included in the curriculum of Faculties of Medicine in various countries, including Spain.

In conclusion, the wide scope of interactions among different and extensive vectors linked to the use and benefits of marketed drugs gives Social Pharmacology huge potential to draw conclusions about risk-benefit factors of medication use, providing alert responses, proposing actions for the decision-making process, minimizing the negative impact of drugs, as well as promoting the proper and efficient use of drugs. The discipline of Social Pharmacology includes topics more extensive than those defined by "Phase IV" of the drug development paradigm.

\section{CONFLICT OF INTEREST}

The author confirm that this article content has no conflict of interest.

\section{ACKNOWLEDGEMENTS}

My gratitude to John J. Schrogie MD, clinical pharmacologist, for the revision of this article and his suggestions. We share friendship and the honor of being direct disciples of our mentor, Prof. Louis Lasagna MD, ScD.

\section{REFERENCES}

[1] Wilson CW. The Social implications of Drug Use. J Ir Med Assoc 1969; 62 (379): 1-7.

[2] Lennard HL. A Proposed Program of Research in Sociopharmacology. In: Psychobiological approaches to Social Behaviour. Leiderman PH, and Shapiro D, eds. Stanford University Press 1964; pp. 127-37.

[3] Morgan JP, Zimmer L. The Social Pharmacology of Smokeable Cocaine: Not All It's Cracked Up to Be, In: Crack in America: Demon Drugs and Social Justice. Reinarman C and Levine HG, eds: The Regents of the University of California 1997, chapter 7.

[4] Venulet J. Aspects of social pharmacology. Prog Drug Res 1978; 22: 10-25.

[5] Alloza JL. Family medicine, drug epidemiology and social pharmacology. Med Clín (Barc) 1984; 82: 124-129.

[6] Alloza JL. Social Pharmacology, a new discipline. (Tribune). The Medical Journal (Diario Médico; Madrid, Spain) 2000; May 10 $0^{\text {th }}: 8$.

[7] Montastruc JL. Social pharmacology: a new topic in clinical pharmacology. Therapie 2002; 57(5): 420-6.

[8] Alloza JL. Social pharmacology: conceptual remarks. Drug Inf J 2004; 38: 321-29.

[9] Ngoundo Mbongue TB, Sommet A, Pathak A, Montastruc JL. Medicamentation of society, non-diseases and non-medications: a point of view from social pharmacology. Eur J Clin Pharmacol 2005; 61; 309-13.

[10] Maiti R, Alloza J. Social pharmacology: expanding horizons. Indian J Pharmacol 2014; 46:246-50.

[11] Alloza JL. Clinical and Social Pharmacology. Postmarketing Period. (Ed). Editio Cantor, Aulendorf, Germany 1985. (ISBN 387193-081-4).

[12] Volodina A, Bertsche T, Kostev K, Winkler V, Haefeli WE, Drug utilization patterns and reported health status in ethnic German migrants (Aussiedler) in Germany: a cross-sectional study. BMC Public Health 2011; 11: 509-15.

[13] Experimental Technology Incentives Program. The Experiment in Post-Marketing Surveillance of Prescription Drugs: An Initial Status Report. Washington DC: National Bureau of Standards; 1982 . 
[14] Leape LL. Reporting of adverse events. N Engl J Med 2002; 347:1633-8.

[15] Lasagna L. A plea for the naturalistic study of medicines. Eur $\mathbf{J}$ Clin Pharmacol 1974; 7 : 153-4.

[16] Alloza JL. A naturalistic study on post-operative acute pain: comparison between two standard narcotic analgesics (morphine and meperidine). Pain (Dolor) 1987; 2: 55-61.

[17] Lasagna L. Phase IV: the opportunity and the challenge. In: Burley D, Haward C, Mullinger B, Ed. The Focus for Pharmaceutical Knowledge. The Proceedings of the $6^{\text {th }}$ International Meeting of Pharmaceutical Physicians. Houndmills, U.K.: MacMillan Press Ltd 1988: pp. 115-8.

[18] Temple RJ, Jones JK, Crout JR. Adverse effects of newly marketed drugs. N Eng J Med 1979; 300: 1046-7.

[19] Alloza JL. Opiophobia and cancer pain. Lancet 1993; 341: 1474-5.

[20] Nguyen JK, Fouts MM, Kotable SE, Lo E. Polypharmacy as a risk factor for adverse drug reactions in geriatric nursing home residents. Am J Geriatr Pharmacother 2006; 4: 36-41.

[21] Rucker TD. Drug-utilization review: Moving toward an effective and safe model. In: Morgan JP, Kagan DC, ed. Society and Medication: Conflicting Signals for Prescribers and Patients. Lexington, MA: Lexington Books 1983; pp. 25-51.

[22] Rucker TD. Drug utilization review: Guidelines for program development. In: Alloza JL, ed. Clinical and Social Pharmacology: Postmarketing Period. Aulendorf, Germany: Editio Cantor 1985; pp. 57-65.

[23] Sriwatanakul K, Weis OF, Alloza JL, Kelvie W, Weintraub M, Lasagna L. Analysis of narcotic analgesic usage in the treatment of postoperative pain. JAMA1983; 250: 926-9.

[24] Weintraub M. Intelligent noncompliance with special emphasis on the elderly. Contemp Pharm Pract 1981; 4: 8-11.

[25] Haynes RB, McDonald HP, Garg AX. Helping patients to follow prescribed treatment. JAMA 2002; 288: 2880-3.

[26] Rucker TD. The formulary process at it relates to drug utilization review. P \& T1992; 17: 646-57.

[27] Nash DB, Catalano ML, Wordell CJ. The formulary decisionmaking process in a US academic medical center. Pharmaco Econ 1993; 3: 22-35.

[28] Mashford ML. Drug information and therapeutic guidelines: A second opinion before prescribing. In: Alloza JL, ed. Communication in Health Care: Drug Information. III International Medical Pharmaceutical Meeting. Madrid, Spain: Madrid Doctors' Association 1995; pp. 12-6.

[29] Johnson KB, Hirshfeld EB, Ile ML, et al. Legal Implications of Practice Parameters. Chicago, IL: American Medical Association 1990.

[30] Tolpin HG. Cost-benefit assessment of pharmaceutical products. Drug Inf J1988: 22: 281-92.

[31] Cooke J. The practical impact of pharmacoeconomics on institutional managers. Pharmaco Econ 1994; 6: 289-97.

[32] Schrogie JJ. Outcomes assessment. In: Johnson NE, Nash DB Ed. The Role of Pharmacoeconomics in Outcomes Management. Chicago, IL: American Hospital Publishing Inc 1996; pp. 9-22.

[33] Gibbong JH. Evaluation of the Oregon Medicaid Proposal. Washington, DC: U.S. Congress, Office of Technology Assessment 1992.

[34] Martinez ME, Jacobs ET, Baron JA, Marshall JR, Byers T. Dietary supplements and cancer prevention: balancing potential benefits against proven harms. J Natl Cancer Inst 2012; 10; 732-39.

[35] Ma Q, Lu AY. Pharmacogenetics, pharmacogenomics, and individualized medicine. Pharmacol Rev 2011; 63(2): 437-59.

[36] Marshall A. Laying the foundations for personalized medicines. Nature Biotech 1997; 15: 954-7.

[37] Yan Q, Hunt CA. Preventing adverse drug events (ADEs): the role of computer information systems. Drug Inf J 2000; 34:1247-60.

[38] Maciá C, Paredes MB, Poncela MP, Alvarez MA, Castaño G, Venta R. Serum cortisol concentrations in acute non-critically ill patients measured in three periods of the day. Med Clín (Barc) 2001; 117: 254-6.

[39] Rylance GW. Prescribing for infants and children. Br Med J 1988; 296: 984-6.

[40] Berd LA, Lipton Hl, Bird JA. Characterization of geriatric drugrelated hospital readmissions. Med Care 1991; 29: 989-1003.

[41] Leape LL, Woods DD, Hatlie MJ, Kizer KW, Schroeder SA, Lundberg GD. Promoting patient safety by preventing medical error. JAMA 1998; 280: 1444-7.

[42] Fink III JL. Compounding versus manufacturing in pharmacy practice: a regulatory challenge. J Pharm Pract 1995; VIII/3:103114.

[43] Conlan MF. Compounding vs. manufacturing. Where is the line? Drug Topics1992; 46-52.

[44] Herbal Prescriptions. The promises and pitfalls. Consumer Reports1999; pp. 44-8.

[45] Eisenberg D, Davis RB, Ettner SL, et al. Trends in alternative medicine use in the United States, 1990-1997. JAMA 1998; 280: 1569-75.

[46] Scheid V. The globalization of Chinese medicine. Lancet 2000; (Suppl. 1999); 354: siv10.

[47] Parfit T. Russian scientists voice concern over Stem-cell cosmetics. Lancet 2005; 386: 1219-20.

[48] Eisenberg DM. Advising patients who seek alternative medical therapies. Ann Int Med 1997; 127: 61-9.

[49] Hróbjartsson A, Gotzche P. Is the placebo powerless? N Engl J Med 2001; 344: 1594-602.

[50] Hufford MR. Placebo effects, memory, and the value of real-time data in drug development. App Clin Trials 2002; 34-43.

[51] Woloshin S, Schwartz LM, Tremmel J, Welch HG. Direct-toconsumer advertisements for prescription drugs: What are Americans being sold? Lancet 2001; 358: 1141-6.

[52] Dhalla I, Laupacis. Moving from opacity to transparency in pharmaceutical policy. CMAJ 2008; pp. 428-31.

[53] Moynihan R. The invisible influence. BMJ 2008; 336: 416-7.

[54] Alloza JL, Lasagna L. A comparison of drug product information in four national compendia. Clin Pharmacol Ther 1983; 33: 269-77.

[55] Shannon ME, Malecha SE, Cha AJ, Moody ML. Evaluation and critical appraisal of a random sample of drug information practice in United States academic and industry medical information centers. Drug Inf J 2000; 334: 1133-8.

[56] Albert T. Written information for patients. Lancet 2000; 356: 434.

[57] Bradbury J. UK panics over phthalates in babymilk formulae. Lancet 1996; 347:1541.

[58] Moynihan R, Bero L, Ross-Degnan D, et al. Coverage by the news media of the benefits and risks of medications. N Engl J Med 2000; 342: 1645-50.

[59] McLellan F. Like hunger, like thirst: patients, journals, and the Internet. Lancet1998; 352 (Suppl II): sii 39-43.

[60] Szalavitz M. Web sites and misinformation about illicit drugs. N Engl J Med 2001; 345:1710.

[61] Alloza JL, Formigos JA. Information about prescription drugs in Spanish language websites on the internet is incomplete. Clin Pharmacol Ther 2007; 81 (Suppl. 1): S67.

[62] Orellana C. German doctors links with drug firm investigated. Lancet 2002; 359: 1039.

[63] Villanueva P, Peiro S, Libero J, Pereiro I. Accuracy of pharmaceutical advertisements in medical journals. Lancet 2003; 361: 27-32.

[64] Alloza JL. Social pharmacology and drug overregulation. Med Clin (Barc) 2005; 124: 379-82.

[65] Schiff GD, Rucker TD. Computerized prescribing. Building the electronic infrastructure for better medication usage. JAMA 1998; 279: 1024-29.

[66] Alloza JL. To Dr. Louis Lasagna, tutor of clinical pharmacologists, with admiration and respect. Med Clin (Barc) 1997; 109: 27-30. 